\title{
Design and Development of Knowledge Based System for Integrated Maintenance Strategy and Operations
}

\author{
Milana Milana, M Khurshid Khan and J Eduardo Munive-Hernandez \\ ${ }^{1}$ School of Engineering, Faculty of Engineering and Informatics, University of Bradford, Bradford, UK \\ ${ }^{2}$ Faculty of Engineering, State University of Padang, Padang, Indonesia
}

\begin{abstract}
The importance of maintenance has escalated significantly by the increase in automation in manufacturing processes. This condition changed the perspective of maintenance from being considered as an inevitable cost to being seen as a key business function to drive competitiveness. Consequently, maintenance decisions need to be aligned with the business competitive strategy as well as the requirements of manufacturing/quality functions in order to support manufacturing equipment performance. Therefore, it is required to synchronise the maintenance strategy and operations with business and manufacturing/quality aspects. This article presents the design and development of a Knowledge Based System for Integrated Maintenance Strategy and Operations. The developed framework of the Knowledge Based System for Integrated Maintenance Strategy and Operations is elaborated to show how the Knowledge Based System for Integrated Maintenance Strategy and Operations can be applied to support maintenance decisions. The knowledge-based system integrates the Gauging Absences of Prerequisites methodology in order to deal with different decision-making priorities and to facilitate benchmarking with a target performance state. This is a new contribution to this area. The Knowledge Based System for Integrated Maintenance Strategy and Operations is useful in reviewing the existing maintenance system and provides reasonable recommendations for maintenance decisions with respect to business and manufacturing perspectives. In addition, it indicates the roadmap from the current state to the benchmark goals for the maintenance system.
\end{abstract}

Keywords

Integrated maintenance strategy and operations, business, manufacturing, knowledge-based system, benchmarking 


\section{Introduction}

The manufacturing function has been widely recognised as one of the key drivers of business competitiveness (Skinner, 1969), contrasting with the view organisations have about the maintenance function. As long as the manufacturing function worked to the expected performance, the maintenance function was not considered as a key function. Instead, the maintenance function was required and considered as an inevitable cost only when the manufacturing processes deteriorated, the quality of products decreased, the production target was not achieved and the corrective action consumed the production budget for repairs.

The significant growth of technology has led many companies to implement the automation of equipment and processes to improve their operational performance (Sanchez and Perez, 2005). Consequently, the important issue is not only the way of adopting advanced technology into the system but also ensuring that all necessary equipment work properly. According to these needs, the maintenance function is recognised to play a principal role to ensure that equipment provides the expected level of service (Marquez, 2007).

The research of maintenance strategy and operations lies on two major technical aspects: maximising availability (Patra, 2007) and minimising cost (Salonen and Deleryd, 2011). Since the significant growth of technology has increased the maintenance role as one of business drivers, the research of maintenance strategy and operations is then aligned with business strategy (Galar et al., 2011; Narayan, 2012; Simoes et al., 2016). Similar with the Knowledge Based System for Integrated Maintenance Strategy and Operations (KBIMSO), the latter research focuses on identifying key aspects within the organisation which are related and contributed to maintenance performance, from business strategy to functional levels. The nature of maintenance strategy and operations is configured as an inseparable part of organisational system. However, maintenance decision-making requires to count qualitative as well as quantitative aspects of business level, manufacturing function (as the customer) and maintenance function itself. The recommendations made for maintenance performance improvement also have to consider prioritisation of rectification based on the importance and the severity of such aspects to the organisation system performance.

This article aims to present the design and development of a KBIMSO. The KBIMSO is developed through one of the Artificial Intelligence applications, the knowledge-based (KB) system, using the rule-based approach. It uses a hybrid approach by combining the KB system and Gauging Absences of Prerequisites (GAP) methodologies which have not been carried out in the past to support the maintenance decisionmaking. It can deal with a large number of variables across different perspectives. The KB rules are generated to find and structure the important variables related to maintenance decisions. Meanwhile, the GAP analysis is embedded into the KB rules to prioritise the crucial factors to be rectified in order to improve the system performance to a benchmark standard. The KBIMSO is also complemented with an explanation facility which consists of additional knowledge to support KB rules in order to avoid ambiguity and fuzziness. Therefore, the KBIMSO can be used as a knowledge storage for managers to retrieve and ascertain how the maintenance decisions were made and which factors were considered to reach the final decisions. With this Artificial Intelligence application, the KBIMSO provides fast, accurate and consistent results in terms of assisting the decision-making process.

\section{Overview of maintenance}

Maintenance is defined as the combination of technical, administrative and managerial actions during the life cycle of equipment to sustain its performance level or to restore it to its designed functionality (British Standard 13306, 2010; Dhillon, 2002). Maintenance is also defined from a failure perspective. Failure is 
simply defined as the inability of a piece of equipment, a plant or a system to work at its expected performance (Smith and Hinchcliffe, 2004). Therefore, the existence of maintenance function is to increase reliability, prevent failure or take countermeasures to minimise failure impact on equipment, manufacturing processes, quality, environment and hence the business performance.

Generally, maintenance policies are only distinguished by corrective maintenance (CM) and preventive maintenance (PM). Smith and Hinchcliffe (2004) defined these policies as unplanned and pre-planned maintenance, respectively. However, given the different implementation approaches of PM, this maintenance policy can be further differentiated. CM was generally recognised as the reactive and unplanned maintenance approach, which focused on repairing breakdowns (Swanson, 2001). In contrast, PM is based on the reliability characteristic of components that enables the maintenance engineer to plan and schedule regular checking and reconditioning before breakdowns occur (Bevilacqua and Braglia, 2000). Predictive maintenance $(\mathrm{PdM})$ is intended to avoid potential failure through threshold indicators and monitoring (e.g. vibration, temperature and sound). Once the threshold is achieved, the signal is sent to the maintenance control system to indicate that deterioration is in progress. Aggressive maintenance (AgM) is generated from the total productive maintenance (TPM) approach (Swanson, 2001). In AgM, the new or existing equipment is modified or designed by a multi-disciplined team. The new designed equipment is supposed to have predominance of high reliability, high maintainability, low maintenance resource equipment and low routine servicing (Tsang, 2002).

\section{Relationship of maintenance with manufacturing and business perspectives}

Awareness about the impact of maintenance in achieving business goals has been proven by several research-ers in recent times (Pinjala et al., 2006; Pintelon et al., 2006; Swanson, 2001). The strong relationship between maintenance and manufacturing is firmly visible within a manufacturing plant in order to keep manufacturing assets working to their expected performance.

As interrelated functions, maintenance and manufacturing work collaboratively to achieve the company's objectives. The main role of maintenance is to support the manufacturing function in fulfilling demand by retaining its production capacity. Gulati (2013) emphasised that the implementation of best practice maintenance can improve performance, competitiveness and market share. Building on past research, this article presents a KB methodology required to make maintenance decisions by referring to key contributing elements in the maintenance function, manufacturing function and business perspective.

\section{The KBIMSO model}

Considering a number of contributing elements in maintenance strategy and operations, the challenge to make informed maintenance decisions can be based on three main points. First, determine the targets and optimal conditions to be reached. Second, identify the pre-requisites to achieve the target (benchmark) result. Third, enable the maintenance staff to support the complex decision-making process, as there are many elements which need to be considered at the same time, through the use of a KB system. The KBIMSO uses a number of methodologies which are discussed below.

\section{KB system}

Decision-making requires knowledge and expertise retrieved from the experts on that particular area. Unfortunately, such knowledge might be lost when they leave the organisation (Korposh et al., 2011; Turban et al., 2008). Therefore, a KB system is pro-posed to imitate the thinking process of experts to generate a reasonable conclusion. It works intelligently in recommending solutions to problems (Liao, 2005). The 
solution proposed by a KB system should be as valid as a solution from a domain expert (Ammar-Khodja et al., 2008).

A KB system generally consists of facts, rules, explanation facility and knowledge acquisition and representation facility. Expressing facts in the form of rules is done through the generation (knowledge) of rules using IF, AND, THEN and OR statements. These rules are generated by the knowledge engineer and their interaction with experts in the domain of the application area. These rules should be clear, expressive, unambiguous and straightforward (Hopgood, 2001). To apply the rules, a system requires access to facts that can be retrieved from a database, connected sensor or interactive user. The explanation facility contains the additional information and knowledge to assist the users obtaining the correct perception towards the issues presented. This explanation facility consists of standardised definitions and statements which assist the users to understand the given question and eliminate any 'fuzziness' in the interpretation (Khan and Wibisono, 2008). Knowledge acquisition and representation aims to ease in reasoning and understanding the relationship between elements of the knowledge base (Jones, 2008).

\section{GAP}

The GAP is a benchmarking technique used to identify and assess the performance gap between the current state and a target state in a particular system (Nawawi et al., 2008). It analyses the responses of users regarding the existing condition of organisation. The responses are divided into two categories. The presence of pre-requisite condition is identified as Good Point (GP). In contrast, the absence of any prerequisite conditions is identified as Bad Points (BPs), which are then classified hierarchically as Problem Categories (PCs).

The PCs were adopted from Kochhar et al. (1991) with five levels of classification (Khan and Wibisono, 2008). These were expanded to nine levels to get more specific description and clear differentiation of the importance and the severity of any condition to the sys-tem performance (Mohamed and Khan, 2012). The level of the chosen PC for each KB rule is made through discussion with academic experts and relevant industrial practitioners. This reasoning is mentioned in the explanation facility to confirm a reasonable and accurate PC analysis. PC-1 is the most important, while PC-9 is the least important as it does not have any effect on the system sustainability. The identification and subsequent elimination of these BPs/PCs will lead to a benchmark implementation.

\section{KBIMSO framework}

KB systems have been used widely for engineering purpose (Ma et al., 2013; Patel et al., 1997; Prasad, 2014; Prasad, 2016; Torres et al., 2013) and manufacturing management purpose (Aldairi et al., 2016; Milana et al., 2014b; Nawawi et al., 2013; Wibisono and Khan, 2016). They have successfully provided consistent solutions on specific problems, reducing time in decision-making, supporting knowledge integration and knowledge sharing and avoiding loss of knowledge from experts and employees (Wibisono and Khan, 2016). Prasad (2014) demonstrated the use of KB systems on product development. It can reduce time and efforts by connecting knowledge from multidisciplinary experts. Similarly, Ma et al. (2013) and Torres et al. (2013) also used the KB system method to integrate multidisciplinary knowledge into the product conceptual design. Moreover, they use the KB systems to accommodate customers' needs in design activities and support decisions in computer-aided design systems.

The combination of KB systems-GAP methodologies for hierarchical decision-making has been applied in recent years in the area of supply chain management (Udin et al., 2006), performance measurement system (Khan and Wibisono, 2008), lean manufacturing (Nawawi et al., 2008), low-volume automotive manufacturing (Mohamed and Khan, 2012), green manufacturing (Nawawi et al., 2013) and sustainable buildings (Aldairi et al., 2016). However, the development of the KB systems-GAP methodologies is new and novel in the area of 
maintenance, particularly in developing an integrated maintenance strategy and operations linked to manufacturing, quality and business perspectives. The integration of GAP into a KB system is considered a novel and suitable methodology to support the decision-making process. The KBIMSO framework is developed to highlight the Key Performance Indicators (KPIs) of business, manufacturing and maintenance perspectives which significantly influence maintenance performance (Milana et al., 2014a), as presented in Figure 1.

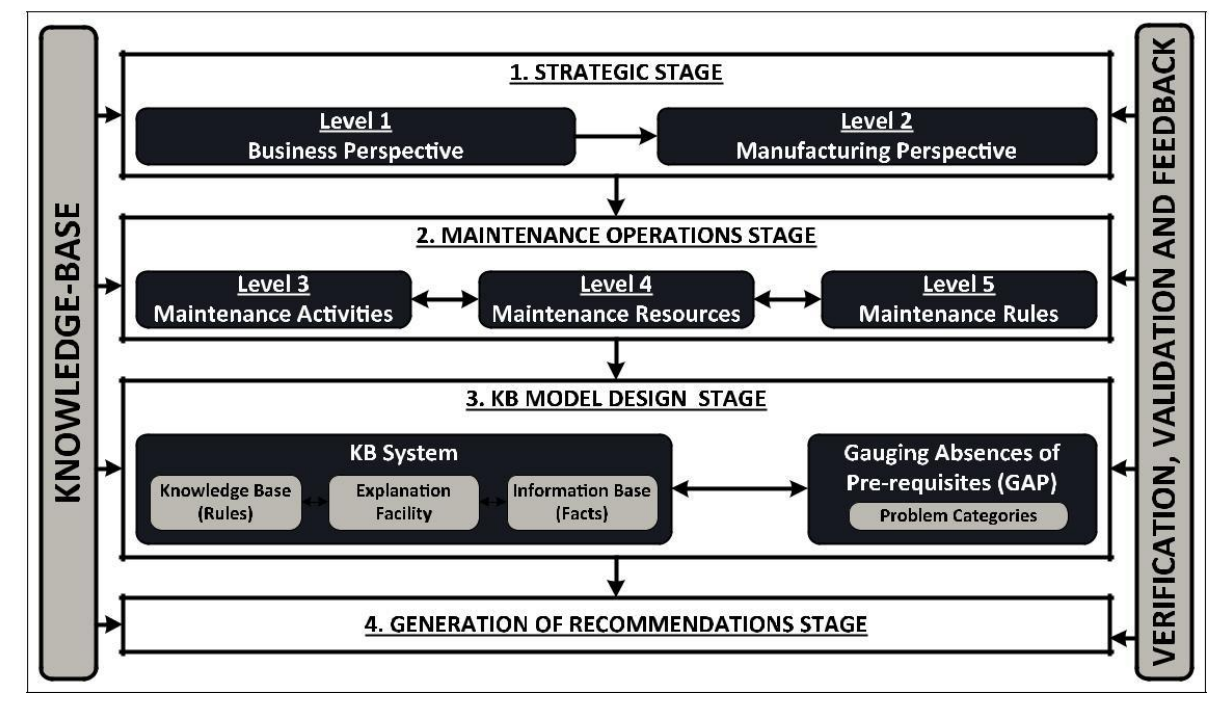

Figure 1. KBIMSO framework with the embedded KB system.

The KBIMSO framework presents the process to develop the KBIMSO model. There are four stages required in this KBIMSO to reach the recommendation for maintenance strategy and operations. The first stage is Strategic Stage. This stage is intended to identify the critical aspects or KPIs on business level (Level 1) and manufacturing function (Level 2) as the guidelines for maintenance decision-making. Meanwhile, the second stage, Maintenance Operations Stage, focuses on maintenance perspectives. It examines KPIs of maintenance elements in terms of maintenance activities (Level 3), maintenance resources (Level 4) and maintenance rules (Level 5). The third stage, KBIMSO Model Design Stage, formulates all the KPIs obtained from the first two stages through the hybrid KB systems-GAP methodologies. On this stage, the KB rules are generated for each level, and the criticality of each rule is categorised based on GAP analysis. The final step is Recommendation. After KB rules are populated, the recommendations are generated to help the maintenance manager identifying critical aspects on the maintenance function that need improvement and rectification. The further discussion of this framework is detailed in the next section.

\section{Development of KBIMSO model}

The development of KBIMSO model is derived from the KBIMSO framework, as presented in Figure 2. The different elements in the business perspective, manufacturing/quality perspective and maintenance perspective are structured in modules. These are further expanded into sub-modules to present the KPIs contributing to the KBIMSO. The business and manufacturing perspectives in the KBIMSO framework are at Level 1 and Level 2 in the Strategic Stage. In addition, three levels of the maintenance perspective - Level 3, Level 4 and Level 5 - are presented through the Maintenance Operations Stage. 


\section{Level 1 - Business Perspective Module}

The first level in the Strategic Stage is Business Perspective Module, as the flowchart shown in Figure 3.

Level 1 - Business Perspective Module adopts the Balanced Scorecard (BSC) approach to provide the overall business performance measurement through four perspectives: financial, customer, internal business process and learning and growth. These four perspectives are able to effectively represent existing business performance and help to identify the prospective achievement in the future (Kaplan and Norton, 1996). The BSC approach facilitates to translate the company statements into functional strategies. Thus, this approach allows identifying the business requirement towards manufacturing and maintenance in the Business Perspective Module of the KBIMSO. The Company Statement Analysis complements this module for articulating the company statement in influencing the overall organisation culture and performance.

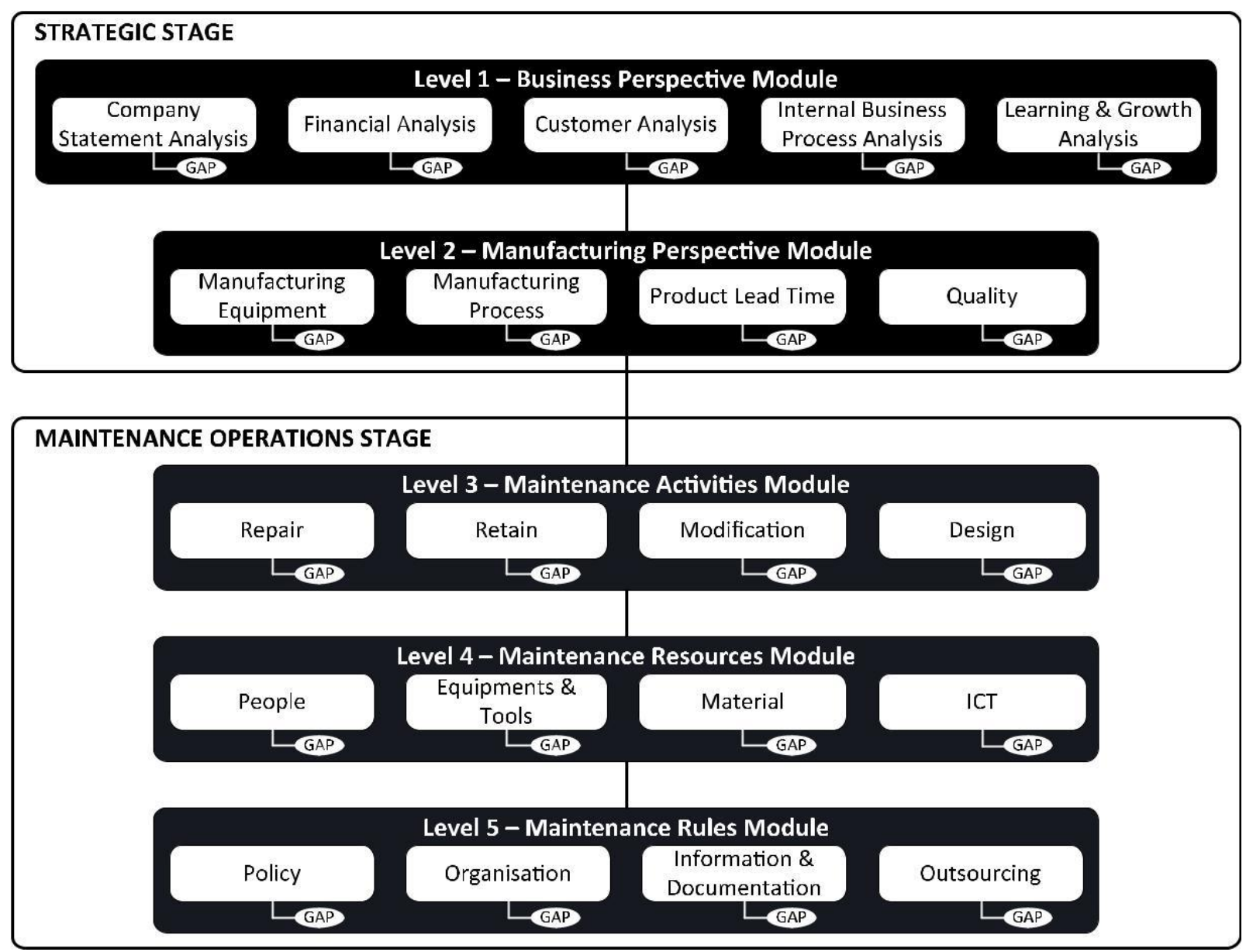

Figure 2. Structure of KBIMSO model. 


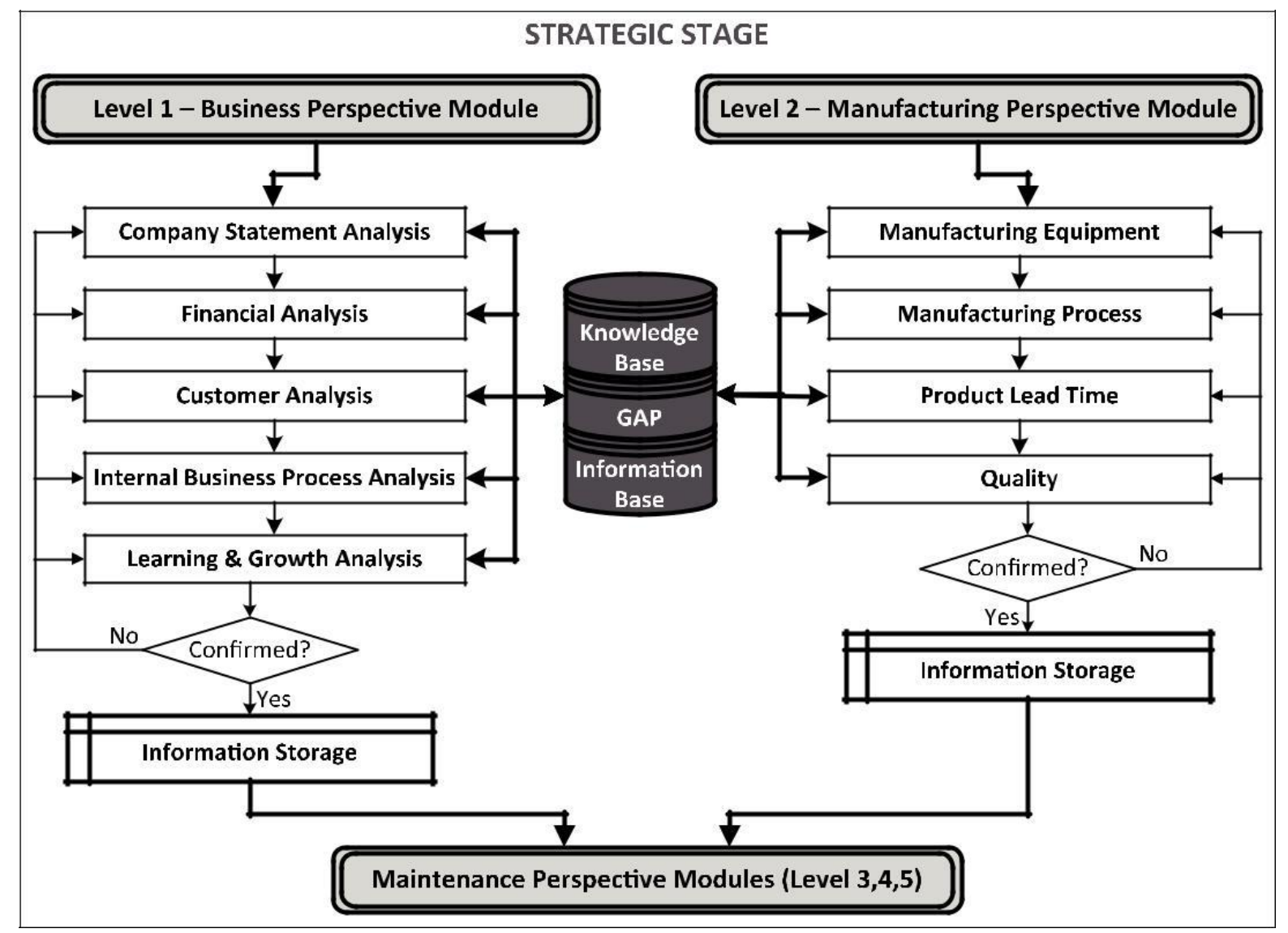

Figure 3. Flowchart of Strategic Stage (Levels 1 and 2). 
After identifying the important aspects on business perspectives, by referring to the KBIMSO framework in Figure 1, the next stage is developing KB model. On this stage, KB rules are generated, and their criticalities are identified through GAP analysis. For illustration purposes, only some basic KB rules related to the

Company Statement Analysis Sub-Module are presented below:

IF Top-Level Management members understand the value of company statements (Yes: GP; No: PC-1) AND Top-Level Management can interpret the value of company statement relating to their job (Yes: GP; No: PC1)

AND Middle-Level Management members under-stand the value of company statements (Yes: GP; No: PC1)

AND Middle-Level Management can interpret the value of company statement relating to their roles (Yes: GP; No: PC-1)

AND Lower Level Management members understand the value of company statements (Yes: GP; No: PC-3) AND Lower Level Management can interpret the value of company statement relating to their roles (Yes: GP; No: PC-3)

AND There is an event to explain the value of com-pany statements to new members of company (Yes: GP; No: PC-2)

THEN Values of company statements are understood appropriately by members of company and implemented in their activities.

OR Values of company statements are not fully understood by members of company with indication of ' $x$ ' PC1 , ' $y$ ' PC-2 and ' $z$ ' PC-3 ( $x, y$ and $z$ represent the number of problem on each $P C)$

OR Values of company statements are not under-stood by members of company

To arrive at a THEN statement, all IF and AND statements should be present. In the case, where some or all of them are absent, the KB system logic chooses the OR statement. The above KB rules emphasise the dissemination of company statements to company members at different management levels. Top- and Middle-Level Managements play the most important role in the company, which determine the success of value and strategy implementation (Hokoma et al., 2008). Therefore, the absence of these points is classified as BP with PC-1. This PC indicates a critical negative impact on the company's overall performance, including the maintenance function. In this way, the KB rules determine the presence (GP) or the absence (BP, along with the corresponding PC) of a pre-requisite. An initial result of GAP analysis for Business Perspective Module is presented in Table 1. As the KB rules are populated, the results are analysed to generate recommendations, as referred in Figure 1. Furthermore, those stages are repeated on each level of KBIMSO.

A total of $234 \mathrm{~KB}$ rules have been designed and developed for this particular module. As the results shown in the Business Perspective Module, out of $234 \mathrm{~KB}$ rules, there are $179 \mathrm{GPs}$ and $55 \mathrm{BPs}$. The BPs are further classified into PCs as follows: 19 PC-1, 15 PC-2, 6 PC-3 and 3 PC-4. The majority of these BPs occur in the three sub-modules: Learning and Growth Analysis (18 BPs), Internal Business Process Analysis (15 BPs) and Customer Analysis (12 BPs). This indicates that there are some major aspects to be improved in disseminating and integrating the value of company statements to enhance company culture and staff behaviour. The Learning and Growth Sub-Module is noted as the most problematic area with 18 BPs (6 PC1, 5 PC-2, 3 PC-3, 1 PC-4, 1 PC-5 and 2 PC-6). This indicates that the company needs to give more 
attention to improve this area, especially on maintaining Employee's Skill and Satisfaction and refine Work Procedure. The Internal Business Process Sub-Module has 15 BPs (6 PC-1, 2 PC-2, 1 PC-3, 1 PC-5, 1 PC6, 2 PC-7, 1 PC-8 and 1 PC-9) with the biggest priority to improve on After-sale Service (4 PC-1 and 1 PC-3). The Customer Analysis Sub-Module has 12 BPs (4 PC-1, 4 PC-2, 1 PC-3, 2 PC-4 and 1 PC-9). By having six BPs on the first four PCs, Market Share is indicated as the aspect which needs more priority to be solved. Finally, the Financial Analysis Sub-Module shows that the company has only three BPs (one PC-2 and two PC-8). However, these problems mention historical financial records for the company to be aware of and to tackle negative trends.

\section{Level 2 - Manufacturing Perspective Module}

Another factor examined in the Strategic Stage is Manufacturing Perspective, as shown in Figure 3. Maintenance (as the manufacturing's logistic function) needs recommendations from manufacturing function to make maintenance decisions (Simoes et al., 2011). This level corresponds to manufacturing/quality factors which have high interaction with maintenance. It consists of Manufacturing Equipment, Manufacturing Process, Product Lead Time (PLT) and Quality sub-modules. A total of $237 \mathrm{~KB}$ rules have been designed and developed for this module. Each sub-module is generally disaggregated into planning, infrastructure and control aspects. The planning aspect encompasses the core performances required to achieve the benchmarks, the infrastructure aspect emphasises the role of management to support the system performance with commitment and adequate resources and the control aspect focuses on evaluating the achievements and proposing the improvement plan. The KPIs of these aspects on each sub-module will then be recommended by the KB system to the maintenance function as an assistance in describing the expected maintenance performance required to support manufacturing function.

Table 1. Initial result of GAP analysis for Business Perspective Module.

\begin{tabular}{|c|c|c|c|c|c|c|c|c|c|c|c|c|c|}
\hline \multirow[t]{2}{*}{ Sub-module } & \multirow[t]{2}{*}{ KPIs } & \multirow{2}{*}{$\begin{array}{l}\text { Number of } \\
\text { KB rules }\end{array}$} & \multirow{2}{*}{$\begin{array}{l}\text { Good } \\
\text { Points }\end{array}$} & \multirow{2}{*}{$\begin{array}{l}\text { Bad } \\
\text { Points }\end{array}$} & \multicolumn{9}{|c|}{ Problem Category (PC) } \\
\hline & & & & & $\overline{1}$ & 2 & 3 & 4 & 5 & 6 & 7 & 8 & 9 \\
\hline Company & Value Socialisation & 11 & 8 & 3 & 1 & 2 & 0 & 0 & 0 & 0 & 0 & 0 & 0 \\
\hline Statement & Value Integration & 14 & 10 & 4 & 2 & 1 & 1 & 0 & 0 & 0 & 0 & 0 & 0 \\
\hline Analysis & Sub-total & 25 & 18 & 7 & 3 & 3 & 1 & 0 & 0 & 0 & 0 & 0 & 0 \\
\hline \multirow[t]{5}{*}{ Financial Analysis } & Leverage Ratio & 15 & 13 & 2 & 0 & 1 & 0 & 0 & 0 & 0 & 0 & 1 & 0 \\
\hline & Liquidity Ratio & 15 & 15 & 0 & 0 & 0 & 0 & 0 & 0 & 0 & 0 & 0 & 0 \\
\hline & Efficiency Ratio & 15 & 14 & 1 & 0 & 0 & 0 & 0 & 0 & 0 & 0 & 1 & 0 \\
\hline & Profitability Ratio & 15 & 15 & 0 & 0 & 0 & 0 & 0 & 0 & 0 & 0 & 0 & 0 \\
\hline & Sub-total & 60 & 57 & 3 & 0 & 1 & 0 & 0 & 0 & 0 & 0 & 2 & 0 \\
\hline \multirow[t]{3}{*}{ Customer Analysis } & Market Share & 27 & 22 & 5 & 2 & 2 & 1 & 0 & 0 & 0 & 0 & 0 & 0 \\
\hline & Customer Satisfaction & 24 & 17 & 7 & 2 & 2 & 0 & 2 & 0 & 0 & 0 & 0 & 1 \\
\hline & Sub-total & 51 & 39 & 12 & 4 & 4 & 1 & 2 & 0 & 0 & 0 & 0 & 1 \\
\hline Internal Business & Product Innovation & 17 & 12 & 5 & 1 & 2 & 0 & 0 & 0 & 0 & 2 & 0 & 0 \\
\hline \multirow[t]{3}{*}{ Process Analysis } & Process Improvement & 14 & 11 & 3 & 1 & 0 & 0 & 0 & 1 & 1 & 0 & 0 & 0 \\
\hline & After-sale Service & 21 & 14 & 7 & 4 & 0 & 1 & 0 & 0 & 0 & 0 & 1 & 1 \\
\hline & Sub-total & 52 & 37 & 15 & 6 & 2 & 1 & 0 & 1 & 1 & 2 & 1 & 1 \\
\hline Learning and & Technology & 11 & 7 & 4 & 1 & 1 & 2 & 0 & 0 & 0 & 0 & 0 & 0 \\
\hline \multirow[t]{4}{*}{ Growth Analysis } & Employee's Skill and Satisfaction & 13 & 8 & 5 & 2 & 2 & 0 & 0 & 1 & 0 & 0 & 0 & 0 \\
\hline & Procedures & 12 & 7 & 5 & 2 & 1 & 1 & 0 & 0 & 1 & 0 & 0 & 0 \\
\hline & Environmental Issue & 10 & 6 & 4 & 1 & 1 & 0 & 1 & 0 & 1 & 0 & 0 & 0 \\
\hline & Sub-total & 46 & 28 & 18 & 6 & 5 & 3 & 1 & 1 & 2 & 0 & 0 & 0 \\
\hline Total & & 234 & 179 & 55 & 19 & 15 & 6 & 3 & 2 & 3 & 2 & 3 & 2 \\
\hline
\end{tabular}

KPIs: Key Performance Indicators; KB: knowledge based; GAP: Gauging Absences of Prerequisites. 
A brief illustration of the KB rules related to Equipment Sub-Module is presented as follows:

IF There is sufficient capacity available at a regular cost to meet orders (Yes: GP; No: PC-1)

AND There is sufficient capacity available at a regular cost to satisfy demand forecasts (Yes: GP; No: PC-1)

AND Equipment is running all the time within the production period (Yes: GP; No: PC-1)

AND Equipment can produce specified output within the quality tolerance level (Yes: GP; No: PC-1)

AND Equipment is flexible to produce different specification of product in terms of size variation (Yes: GP; No: PC-1)

AND Equipment is flexible to produce different specification of product in terms of material variation (Yes: GP; No: PC-1)

AND Equipment is equipped with operations manual (Yes: GP; No: PC-1)

THEN Equipment is performing satisfactorily within the designed function and specification

OR Equipment is not fully performing within the designed function and specification with indication of ' $x$ ' PC-1 ( $x$ represents the number of problem on PC-1) OR Equipment is not performing satisfactorily within the designed function and specification

The highlighted aspects on Manufacturing Equipment planning are capacity, reliability, flexibility and maintainability. When one of these aspects cannot work at its expected performance, the overall system is disturbed and causes system failure. Therefore, all of the KB rules are assessed by GAP analysis as PC-1 when a pre-requisite condition is not fulfilled. An initial result of the GAP analysis for Manufacturing Perspective Module is presented in Table 2.

Table 2. Initial result of GAP analysis for Manufacturing Perspective Module.

\begin{tabular}{|c|c|c|c|c|c|c|c|c|c|c|c|c|c|}
\hline \multirow[t]{2}{*}{ Sub-module } & \multirow[t]{2}{*}{ KPIs } & \multirow{2}{*}{$\begin{array}{l}\text { Number of } \\
\text { KB rules }\end{array}$} & \multirow{2}{*}{$\begin{array}{l}\text { Good } \\
\text { Points }\end{array}$} & \multirow{2}{*}{$\begin{array}{l}\text { Bad } \\
\text { Points }\end{array}$} & \multicolumn{9}{|c|}{ Bad Point/Problem Category (PC) } \\
\hline & & & & & 1 & 2 & 3 & 4 & 5 & 6 & 7 & 8 & 9 \\
\hline Manufacturing & Equipment Planning & 28 & 22 & 6 & 2 & 1 & 1 & 0 & 2 & 0 & 0 & 0 & 0 \\
\hline \multirow[t]{3}{*}{ Equipment } & Equipment Infrastructure & 18 & 13 & 5 & 1 & 2 & 1 & 1 & 0 & 0 & 0 & 0 & 0 \\
\hline & Equipment Control & 19 & 13 & 6 & 3 & 1 & 0 & 1 & 0 & 1 & 0 & 0 & 0 \\
\hline & Sub-total & 65 & 48 & 17 & 6 & 4 & 2 & 2 & 2 & 1 & 0 & 0 & 0 \\
\hline Manufacturing & Process Planning & 24 & 19 & 5 & 1 & 2 & 1 & 0 & 0 & 0 & 1 & 0 & 0 \\
\hline \multirow[t]{3}{*}{ Process } & Process Infrastructure & 16 & 13 & 3 & 1 & 1 & 0 & 0 & 0 & 1 & 0 & 0 & 0 \\
\hline & Process Control & 15 & 9 & 6 & 2 & 1 & 1 & 1 & 0 & 0 & 1 & 0 & 0 \\
\hline & Sub-total & 55 & 41 & 14 & 4 & 4 & 2 & 1 & 0 & 1 & 2 & 0 & 0 \\
\hline Product Lead & PLT Planning & 18 & 16 & 2 & 1 & 0 & 0 & 0 & 0 & 0 & 0 & 0 & 1 \\
\hline \multirow[t]{3}{*}{ Time (PLT) } & PLT Infrastructure & 13 & 8 & 5 & 2 & 1 & 0 & 0 & 0 & 1 & 0 & 1 & 0 \\
\hline & PLT Control & 16 & 10 & 6 & 3 & 1 & 1 & 0 & 0 & 0 & 0 & 1 & 0 \\
\hline & Sub-total & 47 & 34 & 13 & 6 & 2 & 1 & 0 & 0 & 1 & 0 & 2 & 1 \\
\hline \multirow[t]{4}{*}{ Quality } & Quality Planning & 26 & 24 & 2 & 1 & 0 & 0 & 1 & 0 & 0 & 0 & 0 & 0 \\
\hline & Quality Infrastructure & 16 & 13 & 3 & 0 & 1 & 1 & 1 & 0 & 0 & 0 & 0 & 0 \\
\hline & Quality Control & 28 & 25 & 3 & 2 & 0 & 1 & 0 & 0 & 0 & 0 & 0 & 0 \\
\hline & Sub-total & 70 & 62 & 8 & 3 & 1 & 2 & 2 & 0 & 0 & 0 & 0 & 0 \\
\hline Total & & 237 & 185 & 52 & 19 & 11 & 7 & 5 & 2 & 3 & 2 & 2 & 1 \\
\hline
\end{tabular}

KPIs: Key Performance Indicators; KB: knowledge based; GAP: Gauging Absences of Prerequisites. 
In this module, out of a total of $237 \mathrm{~KB}$ rules, there are $185 \mathrm{GPs}$ and $52 \mathrm{BPs}$. BPs are further classified into PCs as follows: 19 PC-1, 11 PC-2, 7 PC-3 and 5 PC-4 on first four PCs. The Manufacturing Equipment SubModule is noted to have the biggest problem with 17 BPs (6 PC-1, 4 PC-2, 2 PC-3, 2 PC-4, 2 PC-5 and 1 PC-6). By emphasising on critical BPs from PC-1 to PC-4, Equipment Control (three PC-1, one PC-2 and one PC-4) rated on the highest priority to get improvement. The Manufacturing Process Sub-Module follows by containing 14 BPs (4 PC-1, 4 PC-2, 2 PC-3, 1 PC-4, 1 PC-6 and 2 PC-7) with the most critical problem on Process Control (2 PC-1, 1 PC-2, 1 PC-3 and 1 PC-4). Similarly, the PLT Sub-Module with 13 BPs (6 PC-1, 2 PC-2, 1 PC-3, 1 PC-6, 2 PC-8 and 1 PC-9) and the Quality Sub-Module with 8 BPs (3 PC-1, 1 PC-2, 2 PC-3 and 2 PC-4) have their biggest problem on PLT Control and Quality Control, respectively. Overall, it can be concluded that the company has key challenges on the control aspect related to evaluation and improvement plan.

\section{Level 3 - Maintenance Activities Module}

The Maintenance Operations Stage reflects the elements of the maintenance system, which are Maintenance Activities Module, Maintenance Resources Module and Maintenance Rules Module, as the flowchart shown in Figure 4. Maintenance perspectives are intended to specify the best combination of maintenance activities, resources and rules to fulfil the demand of manufacturing function and to achieve the aim of maintenance as a driver of business competitiveness. The KPIs of maintenance perspective modules are classified in a similar way as the Manufacturing Perspective Module, which are planning, infrastructure and control. Maintenance activities is defined as a set of technical process on both manufacturing and maintenance environment to ensure that Manufacturing Equipment can meet its expected performance in acceptable business recommendation during their whole commercial life cycles (Liyanage, 2007). The Maintenance Activities Module encompasses four main activities, which are Repair, Retain, Modification and Design Activities. For illustration, some KB rules related to Repair Sub-Module are presented as follows:

IF The equipment is repaired after its expected life time (Yes: GP; No: PC-1)

AND The equipment is repaired before the functional failure (Yes: GP; No: PC-1)

AND The deterioration of equipment has been detected earlier (Yes: GP; No: PC-1)

AND The equipment is repaired due to run-to-failure approach (Yes: GP; No: PC-1)

AND The action of repairing is done on the planned maintenance schedule (Yes: GP; No: PC-1)

AND The action of repairing is preferable than replacement (Yes: GP; No: PC-1)

THEN The maintenance activity of repair is applied effectively

OR The maintenance activity of repair is not fully applied effectively with indication of ' $x$ ' PC-1 ( $x$ represents the number of problem on PC-1)

OR The maintenance activity of repair is not applied effectively 


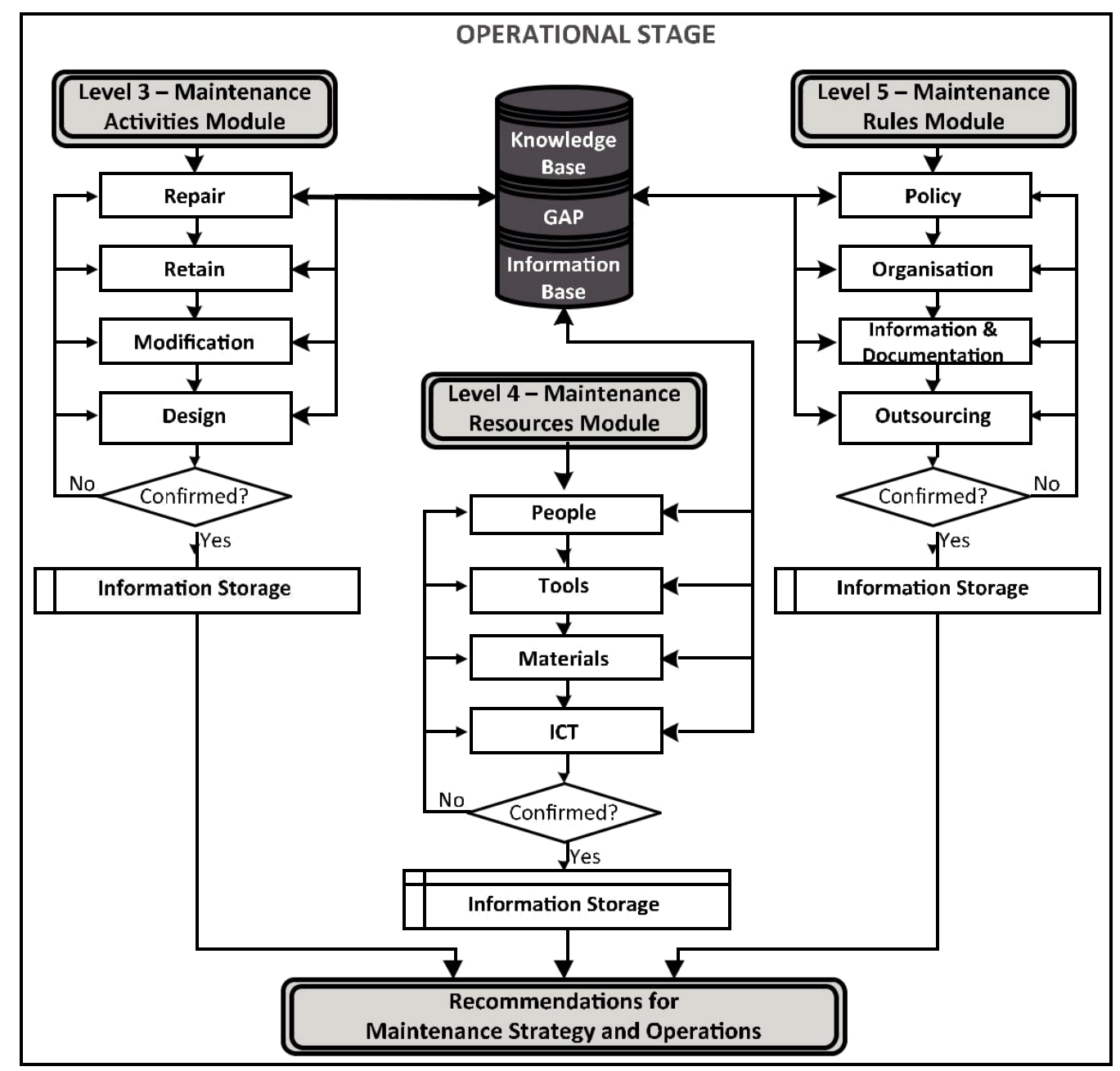

Figure 4. Flowchart of maintenance operations stage (Levels 3, 4 and 5).

The presence of all pre-requisite conditions on those KB rules means that the action of repairing is under schedule and can be managed appropriately. On the other hand, the absence of pre-requisite conditions is rated as PC-1, which implies a very serious problem in a short period of time. An initial result of GAP analysis for Maintenance Activities Module is presented in Table 3. As shown in Table 3, out of $245 \mathrm{~KB}$ rules, there are $189 \mathrm{GPs}$ and $56 \mathrm{BPs}$. The BPs are further classified into PCs as follows: 18 PC-1, 9 PC-2, 7 PC-3 and 4 PC-4. The most problematic areas are identified on Design Sub-Module and Modification Sub-Module, with 18 BPs and 15 BPs, respectively. In Design Sub-Module, there are two PC-1 found on each aspect, but Design Planning contains more critical BPs with two PC-1, one PC-2 and two PC-3. Meanwhile, in Modification Sub-Module, the BPs are spread across all three aspects of KPIs. As for the Design SubModule, the highest problem appears on Modification Planning with three PC-1, one PC-2 and one PC-3. From the pattern of BPs on these two maintenance activities, it can be seen that the company needs to improve its future plans in implementing a proactive maintenance policy.

Furthermore, Repair Sub-Module and Retain Sub-Module are identified as having less problems, with 12 BPs and 11 BPs, respectively. The Repair Control in Repair Sub-Module requires high priority with two PC-1 and one PC-3 being identified. Meanwhile, in Retain Sub-Module, Retain Infrastructure (three PC-1 and one PC-3) is noted as a high-priority aspect for dealing with before the other two. 


\section{Level 4 - Maintenance Resources Module}

To execute maintenance activities, the maintenance resources are obviously required. Unfortunately, the limitation on budget, resources and skilled personnel causes conflict on priority which requires solution on planning and creativity (Dhillon, 2002). Hayes et al. (2005) emphasised trade-offs as an option to deal with resource limitation and resource allocation with respect to business strategy. The discussion on Maintenance Resources Module includes People, Equipment and Tools, Materials and Information and Communication Technology (ICT) Sub-Modules. Some KB rules are shown below to represent People Sub-Module:

IF The technicians are classified based on formal education background (Yes: GP; No: PC-3) AND The technicians are classified based on professional training certification (Yes: GP; No: PC-3)

AND The technicians are classified based on internal performance appraisal (Yes: GP; No: PC-3)

AND The company considers shift pattern to assign technician work load (Yes: GP; No: PC-3)

AND The company considers personal expertise to assign technician work load (Yes: GP; No: PC-3) AND The company considers team capability to assign technician work load (Yes: GP; No: PC-3) THEN The company has commitment to manage and improve maintenance personnel performance

OR The company has less commitment to manage and improve maintenance personnel performance with indication of ' $x$ ' PC-3 ( $x$ represents the number of problem on PC-3)

OR The company has no commitment to manage and improve maintenance personnel performance

Table 3. Initial result of GAP analysis for Maintenance Activities Module.

\begin{tabular}{|c|c|c|c|c|c|c|c|c|c|c|c|c|c|}
\hline \multirow[t]{2}{*}{ Sub-module } & \multirow[t]{2}{*}{ KPIs } & \multirow{2}{*}{$\begin{array}{l}\text { Number of } \\
\text { KB rules }\end{array}$} & \multirow{2}{*}{$\begin{array}{l}\text { Good } \\
\text { Points }\end{array}$} & \multirow{2}{*}{$\begin{array}{l}\text { Bad } \\
\text { Points }\end{array}$} & \multicolumn{9}{|c|}{ Bad Point/Problem Category (PC) } \\
\hline & & & & & 1 & 2 & 3 & 4 & 5 & 6 & 7 & 8 & \\
\hline \multirow[t]{4}{*}{ Repair } & Repair Planning & 17 & 13 & 4 & 1 & 0 & 0 & 0 & 2 & 0 & 0 & 0 & \\
\hline & Repair Infrastructure & 21 & 17 & 4 & 0 & 2 & 0 & 1 & 0 & 0 & 1 & 0 & \\
\hline & Repair Control & 17 & 13 & 4 & 2 & 0 & 1 & 0 & 0 & 1 & 0 & 0 & \\
\hline & Sub-total & 55 & 43 & 12 & 3 & 2 & 1 & 1 & 2 & 1 & 1 & 0 & \\
\hline \multirow[t]{4}{*}{ Retain } & Retain Planning & 25 & 22 & 3 & 1 & 0 & 0 & 1 & 1 & 0 & 0 & 0 & \\
\hline & Retain Infrastructure & 15 & 10 & 5 & 3 & 0 & 1 & 0 & 0 & 0 & 0 & 1 & \\
\hline & Retain Control & 17 & 14 & 3 & 0 & 1 & 0 & 2 & 0 & 0 & 0 & 0 & \\
\hline & Sub-total & 57 & 46 & 11 & 4 & 1 & 1 & 3 & 1 & 0 & 0 & 1 & \\
\hline \multirow[t]{4}{*}{ Design } & Design Planning & 27 & 21 & 6 & 2 & 1 & 2 & 0 & 0 & 1 & 0 & 0 & \\
\hline & Design Infrastructure & 22 & 16 & 6 & 2 & 1 & 0 & 0 & 2 & 0 & 1 & 0 & \\
\hline & Design Control & 19 & 13 & 6 & 2 & 0 & 1 & 0 & 1 & 1 & 1 & 0 & \\
\hline & Sub-total & 68 & 50 & 18 & 6 & 2 & 3 & 0 & 3 & 2 & 2 & 0 & \\
\hline \multirow[t]{4}{*}{ Modification } & Modification Planning & 27 & 21 & 6 & 3 & 1 & 1 & 0 & 1 & 0 & 0 & 0 & \\
\hline & Modification Infrastructure & 23 & 19 & 4 & 2 & 1 & 0 & 0 & 1 & 0 & 0 & 0 & \\
\hline & Modification Control & 15 & 10 & 5 & 0 & 2 & 1 & 0 & 0 & 0 & 1 & 1 & \\
\hline & Sub-total & 65 & 50 & 15 & 5 & 4 & 2 & 0 & 2 & 0 & 1 & 1 & \\
\hline Total & & 245 & 189 & 56 & 18 & 9 & 7 & 4 & 8 & 3 & 4 & 2 & \\
\hline
\end{tabular}

KPIs: Key Performance Indicators; KB: knowledge based; GAP: Gauging Absences of Prerequisites.

The absence of each KB rule above is categorised as PC-3. It indicates a quite major problem, which is most likely to have pre-requisite to the system and may impact overall system performance after a period of time. An initial result of GAP analysis for Maintenance Activities Module is presented in Table 4. 
As shown in Table 4, there are $239 \mathrm{~KB}$ rules developed in Maintenance Resources Module, with 45 of them categorised as BPs. These BPs consist of 10 PC-2, 6 PC-3, 11 PC-4, 6 PC-5, 5 PC-6, 5 PC-7, 1 PC-8 and 1 PC-9. The largest number of problems is found in Material Sub-Module that reveals 15 BPs (2 PC-2, 2 PC-3, 3 PC-4, 3 PC-5, 2 PC-6 and 3 PC-7). Although it seems to have proportional weight by having same five BPs on its three aspects, Material Planning dominates the first four crucial PCs by having one PC-2 and two PC-4 and followed by Material Control by having two PC-3 and one PC-4. Furthermore, Tools Sub-Module contains 12 BPs (2 PC-2, 3 PC-3, 3 PC-4, 2 PC-5, 1 PC-6 and 1 PC-8). On this sub-module, Tools Control requires rectification more than other two aspects by having two PC-2 and two PC-4. People Sub-Module and ICT Sub-Module have less number of BPs on this

Maintenance Resources Module by containing 11 BPs and 7 BPs, respectively. Focusing on first four PCs, both of them need similar priority to rectify, which is on planning aspect, by having two PC-2 on People Planning and one PC-3 and two PC-4 on ICT Planning.

\section{Level 5 - Maintenance Rules Module}

The discussion about how those maintenance resources are shared and managed in a particular manner to gain the required results should be also taken into account. Maintenance rules are required to support, manage and control maintenance activities and resources. These management elements cannot be separated from the structural and physical maintenance elements in order to achieve successful maintenance strategy and operations (Pinjala et al., 2006). There are four sub-modules discussed in this Maintenance Rules Module, which are Policy Sub-Module, Organisation Sub-Module, Information and Documentation Sub-Module and Outsourcing Sub-Module. The illustration of some KB rules on Policy SubModule is presented as follows:

IF The company has policies or formal documents regarding maintenance (Yes: GP; No: PC-1)

AND Top- and/or Middle-Level Management involved on creating policies (Yes: GP; No: PC-1) AND Topand/or Middle-Level Management involved on policy-related plans/programmes (Yes: GP; No: PC-1)

AND Top- and/or Middle-Level Management involved on reviewing policies (Yes: GP; No: PC-1) AND Lower Level Management involved on developing maintenance system and procedures (Yes: GP; No: PC-1)

AND Lower Level Management involved on deter-mining performance indicators (KPIs) for performance measurement (Yes: GP; No: PC-1)

THEN The company has strong policies to manage and improve maintenance performance

OR The company has weak policies to manage and improve maintenance performance with indication of ' $x$ ' PC-1 (x represents the number of problem on PC-1) OR The company has powerless policies to manage and improve maintenance performance 
Table 4. Initial result of GAP analysis for Maintenance Resources Module.

\begin{tabular}{|c|c|c|c|c|c|c|c|c|c|c|c|c|c|}
\hline \multirow[t]{2}{*}{ Sub-module } & \multirow[t]{2}{*}{ KPls } & \multirow{2}{*}{$\begin{array}{l}\text { Number of } \\
\text { KB rules }\end{array}$} & \multirow{2}{*}{$\begin{array}{l}\text { Good } \\
\text { Points }\end{array}$} & \multirow{2}{*}{$\begin{array}{l}\text { Bad } \\
\text { Points }\end{array}$} & \multicolumn{9}{|c|}{ Bad Point/Problem Category (PC) } \\
\hline & & & & & 1 & 2 & 3 & 4 & 5 & 6 & 7 & 8 & 9 \\
\hline \multirow[t]{4}{*}{ People } & People Planning & 24 & 19 & 5 & 0 & 2 & 0 & 0 & 1 & 0 & 1 & 0 & 1 \\
\hline & People Infrastructure & 18 & 15 & 3 & 0 & 1 & 0 & 1 & 0 & 1 & 0 & 0 & 0 \\
\hline & People Control & 13 & 10 & 3 & 0 & 1 & 0 & 2 & 0 & 0 & 0 & 0 & 0 \\
\hline & Sub-total & 55 & 44 & 11 & 0 & 4 & 0 & 3 & 1 & 1 & 1 & 0 & 1 \\
\hline \multirow[t]{4}{*}{ Tools } & Tools Planning & 24 & 20 & 4 & 0 & 0 & 2 & 1 & 1 & 0 & 0 & 0 & 0 \\
\hline & Tools Infrastructure & 20 & 17 & 3 & 0 & 0 & 1 & 0 & 1 & 0 & 0 & 1 & 0 \\
\hline & Tools Control & 12 & 7 & 5 & 0 & 2 & 0 & 2 & 0 & 1 & 0 & 0 & 0 \\
\hline & Sub-total & 56 & 44 & 12 & 0 & 2 & 3 & 3 & 2 & 1 & 0 & 1 & 0 \\
\hline \multirow[t]{4}{*}{ Materials } & Materials Planning & 27 & 22 & 5 & 0 & 1 & 0 & 2 & 0 & 0 & 2 & 0 & 0 \\
\hline & Materials Infrastructure & 22 & 17 & 5 & 0 & 1 & 0 & 0 & 3 & 1 & 0 & 0 & 0 \\
\hline & Materials Control & 16 & 11 & 5 & 0 & 0 & 2 & 1 & 0 & 1 & 1 & 0 & 0 \\
\hline & Sub-total & 65 & 50 & 15 & 0 & 2 & 2 & 3 & 3 & 2 & 3 & 0 & 0 \\
\hline \multirow[t]{4}{*}{ ICT } & ICT Planning & 28 & 25 & 3 & 0 & 0 & 1 & 2 & 0 & 0 & 0 & 0 & 0 \\
\hline & ICT Infrastructure & 23 & 21 & 2 & 0 & 1 & 0 & 0 & 0 & 1 & 0 & 0 & 0 \\
\hline & ICT Control & 12 & 10 & 2 & 0 & 1 & 0 & 0 & 0 & 0 & 1 & 0 & 0 \\
\hline & Sub-total & 63 & 56 & 7 & 0 & 2 & 1 & 2 & 0 & 1 & 1 & 0 & 0 \\
\hline Total & & 39 & 194 & 45 & 0 & 10 & 6 & 11 & 6 & 5 & 5 & 1 & 1 \\
\hline
\end{tabular}

KPIs: Key Performance Indicators; KB: knowledge based; ICT: Information and Communication Technology; GAP: Gauging Absences of Prerequisites.

Maintenance policies have an important rule to manage maintenance resources in order to achieve maintenance goal. The involvement of Top/Middle-Level Management to establish maintenance policies and Lower Level Management to develop the relevant programmes is very crucial to ensure the clarity of the maintenance programmes to continually support Manufacturing Process. Therefore, the absence of any rules is labelled as PC-1. An initial result of GAP analysis for Maintenance Rules Module is presented in Table 5.

As shown in Table 5, from $227 \mathrm{~KB}$ rules, there are $43 \mathrm{BPs}$ and $184 \mathrm{GPs}$. The BPs are classified into different PCs, which are four PC-1, four PC-2, eight PC-3, eight PC-4, five PC-5, five PC-6, five PC-7, three PC-8 and four PC-9. The most problematic aspect is Policy Sub-Module with 13 BPs (2 PC-1, 2 PC-2, 2 PC-3, 2 PC-4, 1 PC-5, 1 PC-6, 1 PC-7, 1 PC-8 and 1 PC-9). Among those three aspects - planning, infrastructure, control Policy Planning needs to be prioritised on improvement as it contains one PC-1 and two PC-3. Furthermore, Organisation Sub-Module and Outsourcing Sub-Module are having same 11 BPs. While Organisation Control on Organisation Sub-Module is marked as the crucial aspect to be improved by having one PC-1 and one PC-3, Outsourcing Infrastructure on Outsourcing Sub-Module needs more attention than other outsourcing aspects by containing two PC-2. On the last sub-module, Information and Documentation SubModule, there are only eight BPs with none is categorised as PC-1 and PC-2. The most crucial problem on this Information and Documentation aspect is two PC-3 on Information and Documentation Planning.

\section{Conclusion}

The concept of integrated maintenance strategy and operations has gained attention, since the maintenance function is recognised as a key business driver for achieving competitive advantage. The role of the maintenance function for achieving expected reliability and performance levels of manufacturing equipment reflects the strong relationship that must be established between maintenance decisions with the manufacturing/quality function. Therefore, decision-making for maintenance strategy and operations must take into account the manufacturing and business strategic perspectives. 
Table 5. Initial result of GAP analysis for Maintenance Rules Module.

\begin{tabular}{|c|c|c|c|c|c|c|c|c|c|c|c|c|c|}
\hline \multirow[t]{2}{*}{ Sub-module } & \multirow[t]{2}{*}{ KPIs } & \multirow{2}{*}{$\begin{array}{l}\text { Number of } \\
\text { KB rules }\end{array}$} & \multirow{2}{*}{$\begin{array}{l}\text { Good } \\
\text { Points }\end{array}$} & \multirow{2}{*}{$\begin{array}{l}\text { Bad } \\
\text { Points }\end{array}$} & \multicolumn{9}{|c|}{ Bad Point/Problem Category (PC) } \\
\hline & & & & & 1 & 2 & 3 & 4 & 5 & 6 & 7 & 8 & 9 \\
\hline \multirow[t]{4}{*}{ Policy } & Policy Planning & 27 & 23 & 4 & 1 & 0 & 2 & 0 & 0 & 0 & 0 & 1 & \\
\hline & Policy Infrastructure & 14 & 8 & 6 & 1 & 0 & 0 & 2 & 0 & 1 & 1 & 0 & \\
\hline & Policy Control & 28 & 25 & 3 & 0 & 2 & 0 & 0 & 1 & 0 & 0 & 0 & \\
\hline & Sub-total & 69 & 56 & 13 & 2 & 2 & 2 & 2 & 1 & 1 & 1 & 1 & \\
\hline \multirow[t]{4}{*}{ Organisation } & Organisation Planning & 22 & 19 & 3 & 0 & 0 & 1 & 1 & 1 & 0 & 0 & 0 & \\
\hline & Organisation Infrastructure & 13 & 8 & 5 & 1 & 0 & 0 & 1 & 0 & 2 & 0 & 0 & \\
\hline & Organisation Control & 12 & 9 & 3 & 1 & 0 & 1 & 0 & 1 & 0 & 0 & 0 & \\
\hline & Sub-total & 47 & 36 & 11 & 2 & 0 & 2 & 2 & 2 & 2 & 0 & 0 & \\
\hline Information \& & I\&D Planning & 20 & 17 & 3 & 0 & 0 & 2 & 0 & 0 & 0 & 0 & 1 & \\
\hline \multirow[t]{3}{*}{ Documentation (I\&D) } & I\&D Infrastructure & 12 & 10 & 2 & 0 & 0 & 0 & 1 & 0 & 1 & 0 & 0 & \\
\hline & I\&D Control & 16 & 13 & 3 & 0 & 0 & 0 & 2 & 1 & 0 & 0 & 0 & \\
\hline & Sub-total & 48 & 40 & 8 & 0 & 0 & 2 & 3 & 1 & 1 & 0 & 1 & \\
\hline \multirow[t]{4}{*}{ Outsourcing } & Outsourcing Planning & 24 & 20 & 4 & 0 & 0 & 1 & 1 & 0 & 1 & 0 & 0 & \\
\hline & Outsourcing Infrastructure & 19 & 15 & 4 & 0 & 2 & 0 & 0 & 1 & 0 & 1 & 0 & \\
\hline & Outsourcing Control & 20 & 17 & 3 & 0 & 0 & 1 & 0 & 0 & 0 & 0 & 1 & \\
\hline & Sub-total & 63 & 52 & 11 & 0 & 1 & 2 & 1 & 2 & 1 & 1 & 1 & \\
\hline Total & & 227 & 184 & 43 & 4 & 4 & 8 & 8 & 5 & 5 & 2 & 3 & \\
\hline
\end{tabular}

KPIs: Key Performance Indicators; KB: knowledge based; GAP: Gauging Absences of Prerequisites.

A novel KB-based system, incorporating GAP analysis has been designed and developed for achieving a benchmark-integrated maintenance system. In the cur-rent KBIMSO, a total of $1182 \mathrm{~KB}$ rules have been developed for the five main modules. In its design stage, the KBIMSO framework is separated into two main stages: Strategic Stage and Maintenance Operations Stage. The Strategic Stage covers the elements of business and manufacturing perspectives affecting maintenance, while the Maintenance Operations Stage focuses on elements of maintenance strategy and operations. Each level in the KBIMSO structure is expanded into modules and sub-modules for detailing the development of KB rules for all KPIs. This design stage of the KBIMSO provides information required to develop the KBIMSO.

The KBIMSO employs GAP methodology to achieve the benchmark standards. It provides recommendations for all decision makers (e.g. maintenance managers) to prioritise key aspects to improve operations and strategic plans for achieving a benchmark maintenance system implementation. The generality of KB rules makes KBIMSO flexible to be implemented on different maintenance environments. Moreover, it provides precise tracking of how each rule/decision is arrived. For future work, the KBIMSO application will be further developed through additional KB rules and verified in a number of industrial settings in order to ensure that the KBIMSO provides valid, consistent and real-time results.

\section{Declaration of Conflicting Interests}

The author(s) declared no potential conflicts of interest with respect to the research, authorship, and/or publication of this article.

\section{Funding}

The author(s) disclosed receipt of the following financial support for the research, authorship, and/or publication of this article: This study is supported by the Ministry of Research, Technology and Higher Education of the Republic of Indonesia and the University of Bradford, UK. 


\section{References}

Aldairi JS, Khan MK and Munive-Hernandez JE (2016) A hybrid knowledge-based lean six sigma maintenance sys-tem for sustainable buildings. In: Ao S-I, Yang G-C and Gelman L (eds) Transactions on Engineering Technologies. Singapore: Springer, pp. 355-369.

Ammar-Khodja S, Perry N and Bernard A (2008) Process-ing knowledge to support knowledge-based engineering systems specification. Concurrent Engineering 16: 89-101.

Bevilacqua $M$ and Braglia M (2000) The analytic hierarchy process applied to maintenance strategy selection. Reliability Engineering \& System Safety 70: 71-83.

British Standard 13306:2010 (2010) Maintenance-Mainte-nance Terminology.

Dhillon BS (2002) Engineering Maintenance: A Modern Approach. Boca Raton, FL: CRC Press.

Galar D, Parida A, Kumar U, Stenstro"m C and Berges L (2011) Maintenance metrics: A hierarchical model of balanced scorecard. In: International Conference on Qual-ity and Reliability (ICQR), 14-17 September 2011. Bang-kok: IEEE Xplore Digital Library, pp. 67-74.

Gulati R (2013) Maintenance and Reliability Best Practices. New York: Industrial Press.

Hayes R, Pisano G, Upton D, et al. (2005) Operations, Strat-egy, and Technology: Pursuing the Competitive Edge. Hoboken, NJ: John Wiley \& Sons.

Hokoma RA, Khan MK and Hussain K (2008) Investigation into the implementation stages of manufacturing and qual-ity techniques and philosophies within the Libyan cement industry. Journal of Manufacturing Technology Manage-ment 19: 893-907.

Hopgood AA (2001) Intelligent Systems for Engineers and Scientists. Boca Raton, FL: CRC Press.

Jones MT (2008) Artificial Intelligence: A Systems Approach. Hingham, MA: Infinity Science Press LLC.

Kaplan RS and Norton DP (1996) The Balanced Scorecard: Translating Strategy into Action. Boston, MA: Harvard Business School Press.

Khan MK and Wibisono D (2008) A hybrid knowledge-based performance measurement system. Business Process Man-agement Journal 14: 129-146.

Korposh D, Lee Y-C, Wei C-C, et al. (2011) Modeling the effects of existing knowledge on the creation of new knowl-edges. Concurrent Engineering: Research and Applications

19: 225-234.

Liao S-H (2005) Expert system methodologies and applica-tions - a decade review from 1995 to 2004. Expert Systems with Applications 28: 93-103.

Liyanage JP (2007) Operations and maintenance performance in production and manufacturing assets: the sustainability perspective. Journal of Manufacturing Technology Manage-ment 18: 304-314.

Ma J, Hu J, Zheng K, et al. (2013) Knowledge-based func-tional conceptual design: model, representation, and implementation. Concurrent Engineering: Research and Applications 21: 103-120.

Ma'rquez AC (2007) The Maintenance Management Frame-work. London: Springer.

Milana M, Khan MK and Munive JE (2014a) A framework of knowledge based system for integrated maintenance strategy and operation. Applied Mechanics and Materials

564: 619-624.

Milana M, Khan MK and Munive JE (2014b) Development the conceptual design of knowledge based system for integrated maintenance strategy and operation. IOP Con-ference Series: Materials Science and Engineering 65: 012035.

Mohamed NMZN and Khan MK (2012) The development of a hybrid knowledge-based system for the design of a low volume automotive manufacturing (LVAM) system. International Journal of Intelligent Systems Technologies and Applications 11: 17-35.

Narayan V (2012) Business performance and maintenance: how are safety, quality, reliability, productivity and main-tenance related? Journal of Quality in Maintenance Engineering 18: 183-195.

Nawawi MKM, Khan MK and Hussain K (2008) Knowl-edge-based collaborative lean manufacturing management (KBCLMM) system. Journal of KONBiN 5: 145-156.

Nawawi MKM, Mohamed NMZN and Aminuddin ASA (2013) Planning and design of a knowledge based system for green manufacturing management. IOP Conference Series: Materials Science and Engineering 50: 012065. 
Patel J, Prasad B, Singhal S and Yertiz A (1997) Towards the use of knoweldge based engineering system in a concurrent engineering environment. In: Fourth ISPE International Conference on Concurrent Engineering: Research and Applications, 20-22 August 1997. Michigan: Oakland University, pp. 379-388.

Patra AP (2007) RAMS and LCC in rail track maintenance. Licentiate thesis, Lulea University of Technology, Lulea ${ }^{\circ}$.

Pinjala SK, Pintelon L and Vereecke A (2006) An empirical investigation on the relationship between business and maintenance strategies. International Journal of Production Economics 104: 214-229.

Pintelon L, Pinjala SK and Vereecke A (2006) Evaluating the effectiveness of maintenance strategies. Journal of Quality in Maintenance Engineering 12: 7-20.

Prasad B (2014) Knowledge-based enterprising (KBE) strat-egy for lean product development (LPD). IOP Conference Series: Materials Science and Engineering 65: 011002.

Prasad B (2016) Lean, integrated \& connected framework for developing smart products. In: Batalla JM, Mastora-kis G, Mavromoustakis CX and Pallis E (eds) A Hand-book on "Beyond the Internet of Things: Everything Interconnected”. Draft-First Published ed. Heidelberg: Springer, pp. 1-25.

Salonen A and Deleryd M (2011) Cost of poor maintenance: a concept for maintenance performance improvement.

Journal of Quality in Maintenance Engineering 17: 63-73. Sanchez AM and Perez MP (2005) Supply chain flexibility

and firm performance: a conceptual model and empirical study in the automotive industry. International Journal of Operations \& Production Management 25: 681-700.

Simoes JM, Gomes CF and Yasin MM (2011) A literature review of maintenance performance measurement: a conceptual framework and directions for future research. Jour-nal of Quality in Maintenance Engineering 17: 116-137.

Simoes JM, Gomes CF and Yasin MM (2016) Changing role of maintenance in business organisations: Measurement versus strategic orientation. International Journal of Production Research 54: 3329-3346.

Skinner W (1969) Manufacturing-missing link in corporate strategy. Harvard Business Review [Online]. Available at: http://hbr.org/1969/05/manufacturing-missing-link-in-cor-porate-strategy/ar/1 (accessed 17 January 2013).

Smith AM and Hinchcliffe GR (2004) RCM - Gateway to World Class Maintenance. Amsterdam: Elsevier. Swanson L (2001) Linking maintenance strategies to performance. International Journal of Production Economics 70: 237-244.

Torres VH, Ri'os J, Viza'n A, et al. (2013) Approach to integrate product conceptual design information into a computer-aided design system. Concurrent Engineering 21: 27-38.

Tsang AHC (2002) Strategic dimensions of maintenance management. Journal of Quality in Maintenance Engineering 8: 7-39.

Turban E, Volonino L, Mclean E, et al. (2008) Information Technology for Management: Transforming Organizations in the Digital Economy. New York: Wiley.

Udin ZM, Khan MK and Zairi M (2006) A collaborative supply chain management: part 2 - the hybrid $\mathrm{KB} / \mathrm{gap}$ analysis system for planning stage. Business Process Management Journal 12: 671-687.

Wibisono D and Khan MK (2016) Performance measurement system for a manufacturing environment: KB/GAP/AHP approach. International Journal of Robotics and Mechatronics 2: 65-76.

\section{Author biographies}

Milana Milana received her MSc degree in Manufacturing Management from the University of Bradford, Bradford, UK, in 2011. She is currently a PhD candidate in the Automotive Research Centre at University of Bradford. She has been a faculty member of Automotive Engineering at State University of Padang, Indonesia, since 2008. Her research interests include performance measurement, knowledge management and knowledge-based/expert systems with applications in manufacturing system.

M Khurshid Khan received his BEng, PhD and MBA degrees from the University of Bradford in 1983, 1987 and 1997, respectively. His $\mathrm{PhD}$ area of research was experimental and theoretical study of air turbulence. 
During 1987-1990, he worked for Pepsi-Cola International as a Technical Services Manager in the Middle East, Far East and African regions. In 1990, he joined the School of Engineering, University of Bradford, where he is currently a Professor of Manufacturing Systems Engineering. His research interests are in the area of Artificial Intelligence (Al)/Knowledge-Based Systems and their applications to Manufacturing and Quality Systems, Strategy, Planning, Control, Scheduling and Supply Chain Management.

$J$ Eduardo Munive-Hernandez is a lecturer in Advanced Manufacturing Engineering at the Faculty of Engineering and Informatics, University of Bradford. He received his PhD in Total Technology from the University of Manchester Institute of Science and Technology in 2003. His major research interests include the analysis, development and implementation of knowledge management initiatives to support strategic management decisions in the context of manufacturing organisations, their supply chains and other operational functions, including small and medium-sized enterprises (SMEs). 